ScIDice

\section{International Journal of Dentistry and Oral Science (IJDOS) \\ ISSN: 2377-8075}

\title{
Herbals For Tobacco Cessation - A Review
}

Research Article

\section{Leelavathi ${ }^{1 *}$, Dhanraj Ganapathy ${ }^{2}$}

${ }^{1}$ Senior lecturer, Department of Public Health Dentistry, Saveetha Dental College and Hospitals, Saveetha Institute of Medical and Technical Sciences, Saveetha University, Chennai-77,India.

${ }^{2}$ Professor and Head, Department of Prosthodontics, Saveetha Dental College and Hospitals, Saveetha Institute of Medical and Technical Sciences, Saveetha University, Chennai-77,India.

\section{Abstract}

Tobacco usage is one among the preventable cause of morbidity and mortality. Tobacco use is related with various diseases including stroke, lung cancer, cardiovascular and respiratory diseases. Tobacco cessation can reduce premature death and it also improves the quality of life. Smoking cessation is becoming a vitalpart of tobacco control policies and various tobacco cessation programs are initiated that focuses on prevention of tobacco use, diagnosis of tobacco dependence and cessation of tobacco use. Smoking is one of the addictive habits and most of the tobacco users find difficulty in stopping the habit by themselves and they seek professional guidance in tobacco cessation. Behavioural counselling, nicotine replacement therapies, bupropion and varenicline are the commonly used methodsfor smoking cessation. There is not much information available pertaining to the use of natural agents in tobacco cessation and hence this review was done with an aim to explore the role of herbs in smoking cessation.

Keywords: Tobacco Use; Lung Cancer; Smoking Cessation; Herbs

\section{Introduction}

Tobacco use continues to be the major cause of preventable death throughout the world. Nearly 6 million people died because of tobacco use and huge economic loss occurred throughout the world every year. Most of these deaths happen in low- and middle-income countries, and this inequality is expected to extend further over the next few decades. If this trend continue, more than 8 million people will die because of tobacco use by 2030 throughout the world and hence more death would occur if proper actions are not taken[1]. It was reported that there was a decrease in the tobacco use prevalence. Around one third of the population in the world in the age group of 15 years and above used tobacco in the year 2000 and the prevalence of tobacco use was decreased to around one fourth of the population in the year 2015[2].

\section{Tobacco And Nicotine Addiction}

Nicotianarustica and Nicotianatabacum are the plants, from which tobacco is most commonly produced. These plants were identified before eighteen thousand years when the Asians shifted to America. Tobacco was been cultivated all over India and been used as an insecticide in farming, performing religious rituals[3].

Cigarette smoke consists of more than 7,000 chemicals that includes sixty-nine known carcinogens and numerous toxicants involved in various diseases[4,5]. Volume of the puff, blocked ventilation holes and number of puffs per cigarette has a large impact on the levels of carcinogenic, toxic, and addictive compounds delivered to the tobacco user in cigarette smoke. The leaf of the tobaccoconsists of many alkaloid chemicals, among which nicotine contributes the large part. Based on the position of the leaf on the stalk of tobacco and also the type of leaf used in the cigarette the nicotine content of the tobacco product differs. As nicotine is similar to the acetylcholine, neurotransmitter in the brain, they are addictive to humans [5].

Addiction is defined as a chronic, relapsing brain disease that is

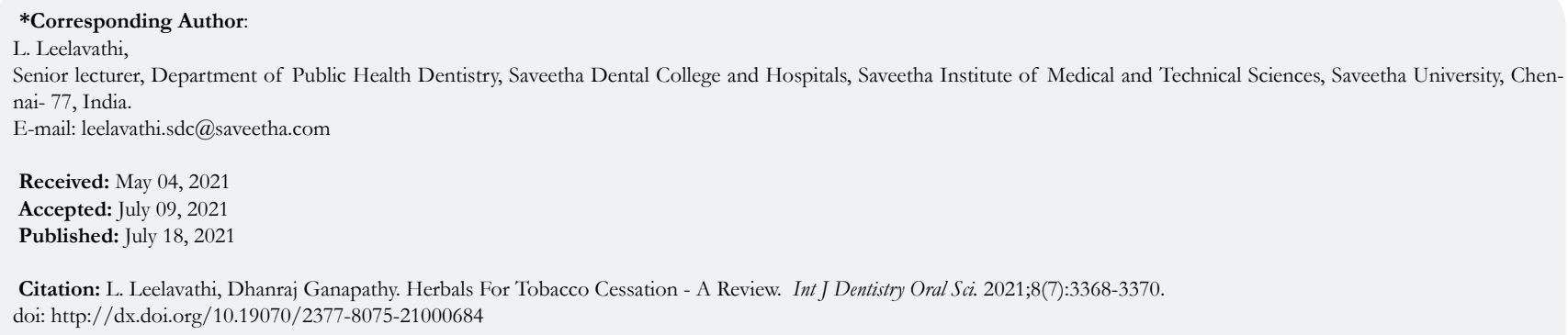

Copyright: L. Leelavathi ${ }^{\circ} 2021$. This is an open-access article distributed under the terms of the Creative Commons Attribution License, which permits unrestricted use, distribution and reproduction in any medium, provided the original author and source are credited. 
represented by compulsive drug seeking and use, regardless of adverse consequences. Drug dependence is an adaptive state that evolves from repeated administration of the drug, which would result in withdrawal upon cessation of the usage of the drug.

Reducing the use of tobacco use needs to be considered as a global health priority. Tobacco use is also cause economic problem and is reported to have an impact of the economy of the world. Tobacco use also threatens sustainable development of the country by increasing poverty in poor households due to decreased income and also increased health care costs. Tobacco control can be achieved by the combined effort of the community, government and public health organisations. Tobacco use was more common among men when compared with women. Though there was an increase in the tobacco control measures, still there is a need to focus on tobacco control measures among marginalised groups[2].

\section{Tobacco Cessation Methods}

Smoking cessation can be done by various methods including quitting the habit without assistance such as cold turkey method or fading technique, pharmacotherapy methods such as nicotine replacement therapies, bupropion or varenicline, and also by behaviouralcounselling. Most of the smokers try to quit the habit on their own without professional guidance, but only 3-6\% of them succeeded in quitting the habit without assistance[6,7]. Behavioural counselling and pharmacotherapies increases the success in quit attempts and it was reported that the combination of behavioural counselling with pharmacotherapies was more effective than the single mode of treatment[8].

E cigarettes is one of the commonly used electronic nicotine delivery systems. They work under the process of heating a liquid to produce an aerosol that is inhaled by the user. The liquid does not contain tobacco but it has nicotine and various other chemicals that may harm anindividual[9].

\section{Alternative Approaches}

Acupuncture has been investigated as an adjunct treatment method for tobacco cessation. Aromatherapy has been reported to be used for smoking cessation and it was stated that vapour inhalation of extracts of black pepper reduce withdrawal symptoms of smoking [70] Hypnosis was reported to be effective for smoking cessation in a study whereas it was reported to be ineffective in few studies[7]. It was reported in a review that practising bellows breath which is termed as Bhastrika Pranayama twice in a day, once in morning and once at night expels the toxic chemicals of tobacco products from lower and upper airways[10].

\section{Ayurvedha And Smoking Cessation}

Ayurveda is a branch of upaveda in Vedic tradition and is very old traditional medicinal system of Hindusinherent to the Indian subcontinent. Ayurveda is known to be a complete medical system that consists of psychological, physical, philosophical, ethical and spiritual health. Ayurveda is known for its concept of self-healing and other than the concept of self-healing, different surgical techniques, massages and usage of medicinal herbs has been practiced in Ayurveda. Various Ayurvedic approaches are reported to be absolutely helpful in decreasing the harmful effects of tobacco[10].

\section{Herbals In Smoking Cessation}

Many of the tobacco cessation medications are costly and that was considered as barrier for smoking cessation treatments in low- and middle-income countries. Also, those medications are related with adverse effects like nausea, dry mouth and sedation. Hence, herbal remedies have been considered as a possible choice for smoking cessation treatmentwhich could be easily accessible, less costlier and have fewer side effects[11].

Herbal remedies were reported to reduce the addictive effects of nicotine in tobacco products by working within the nervous system. Also, they have been used to overcome psychological part of addiction and also withdrawal symptoms[12].

Studies were done to determine the efficacy of St. John's wort in tobacco cessation. It was concluded in the studies that there was no statistical difference in smoking cessation between placebo group and intervention group[13,14].

Arandomised controlled trial was done to analyse the efficacy of mixed herbal tea for smoking cessation and it was concluded that use of mixed herbal tea significantly reduced the number of cigarettes smoked per day and the craving among the intervention group than placebo group[15]. A study was carried out to evaluate the efficacy of a cigarette substitute delivering a vapor of black pepper on smoking cessation, compared to mint/menthol device and placebo. Three hours after inhaling black pepper vapor, craving for cigarettes was significantly relative reduced in control groups when compared with placebo group[16].

Cyanthilliumcinereum has been traditionally used as antipyretic, diuretic, antitussive, anti-haemorrhoid, anti-jaundice, anti-hepatitis and indigestion treatment. A systematic review was done to assess the safety and efficacy of cyanthilliumcinereum for smoking cessation. Cyanthilliumcinereum also called as little iron weed has been included by the Public Health Ministry of Thailand in the National list of herbal medicine. It is been considered as an alternative treatment for tobacco cessation $[17,18]$.

A study was conducted in Thailand to evaluate the efficacy of lime in tobacco cessation when compared with nicotine replacement therapy and it was concluded in the trial that lime could be used as smoking cessation agent. Calamus has abundant traditional applications and has been noted for its medicinal values from olden days. Calamus has been used as a remedy for indigestion, appetite,cardiac arrest, fever and cough. It is also been used as antibacterial agent, antioxidant and also as an antidepressant and this was reported to be due to the presence of bio active components, alpha and beta asarone. Some of the studies found that calamus helps in tobacco cessation, however the mechanism of action of calamus in reducing the tobacco use was not reported $[12,19]$.

\section{Conclusion}

Natural agents are easily available, inexpensive, reported to be effective in tobacco cessation and hence can be helpful for those smokers who are not interested in usingpharmacotherapies. 
Therefore, further studies should be conducted on the determination of the effectiveness of natural agents in tobacco cessation cessation and the role of the natural agents in smoking cessation should be explored.

\section{References}

[1]. World Health Organization. WHO report on the global tobacco epidemic, 2011: warning about the dangers of tobacco. Geneva: World Health Organization; 2011

[2]. World Health Organization. WHO global report on trends in prevalence of tobacco use 2000-2025.

[3]. Balbani AP, Montovani JC. Methods for smoking cessation and treatment of nicotine dependence. Braz J Otorhinolaryngol. 2005 Nov-Dec;71(6):820-7. PubmedPMID: 16878254

[4]. Borgerding M, Klus H. Analysis of complex mixtures--cigarette smoke. ExpToxicolPathol. 2005 Jul;57Suppl 1:43-73. PubmedPMID: 16092717.

[5]. U.S. Department of Health and Human Services. How Tobacco Smoke Causes Disease: The Biology and Behavioral Basis for Smoking-Attributable Disease: A Report of the Surgeon General. Atlanta, GA: U.S. Department of Health and Human Services, Centers for Disease Control and Prevention, National Center for Chronic Disease Prevention and Health Promotion, Office on Smoking and Health, 2010.

[6]. Rigotti NA. Strategies to help a smoker who is struggling to quit. JAMA. 2012 Oct 17;308(15):1573-80. PubmedPMID: 23073954

[7]. Patel AB, Patel AB, Patel BV. Methods of smoking cessation. The Journal of National Accreditation Board for Hospitals \& Healthcare Providers. 2016 Jan 1;3(1):1.

[8]. Stead LF, Koilpillai P, Fanshawe TR, Lancaster T. Combined pharmacotherapy and behavioural interventions for smoking cessation. Cochrane Database Syst Rev. 2016 Mar 24;3:CD008286. PubmedPMID: 27009521.
[9]. WHO report on the global tobacco epidemic 2019. Geneva: World Health Organization; 2019.

[10]. Semwal DK, Mishra SP, Chauhan A, Semwal RB. Adverse health effects of tobacco and role of Ayurveda in their reduction. Journal of Medical Sciences. 2015 Apr 1;15(3):139.

[11]. Lando HA. Promoting tobacco cessation in low-and middle-income countries. Journal of Smoking Cessation. 2016 Jun;11(2):66-9.

[12]. Yarnell E, Abascal K. Botanical remedies for nicotine addiction. Alternative \& Complementary Therapies. 2001 Dec 1;7(6):337-40.

[13]. Sood A, Ebbert JO, Prasad K, Croghan IT, Bauer B, Schroeder DR. A randomized clinical trial of St. John's wort for smoking cessation. J Altern Complement Med. 2010 Jul;16(7):761-7. PubmedPMID: 20590478.

[14]. Parsons A, Ingram J, Inglis J, Aveyard P, Johnstone E, Brown K, et al. A proof of concept randomised placebo controlled factorial trial to examine the efficacy of St John's wort for smoking cessation and chromium to prevent weight gain on smoking cessation. Drug Alcohol Depend. 2009 Jun 1;102(1-3):116-22. PubmedPMID: 19328636.

[15]. Lee HJ, Lee JH. Effects of medicinal herb tea on the smoking cessation and reducing smoking withdrawal symptoms. Am J Chin Med. 2005;33(1):12738. PubmedPMID: 15844840.

[16]. Kitikannakorn N, Chaiyakunapruk N, Nimpitakpong P, Dilokthornsakul P, Meepoo E, Kerdpeng W. An overview of the evidences of herbals for smoking cessation. Complement Ther Med. 2013 Oct;21(5):557-64. PubmedPMID: 24050594.

[17]. Puttarak P, Pornpanyanukul P, Meetam T, Bunditanukul K, Chaiyakunapruk N. Efficacy and safety of Vernoniacinerea (L.) Less. for smoking cessation: A systematic review and meta-analysis of randomized controlled trials. Complement Ther Med. 2018 Apr;37:37-42. PubmedPMID: 29609935.

[18]. Wongwiwatthananukit S, Benjanakaskul P, Songsak T, Suwanamajo S, Verachai V. Efficacy of Vernoniacinerea for smoking cessation. Journal of health research. 2009;23(1):31-6.

[19]. Nisaa ZU, Zafar A. Efficacy of a smoking cessation intervention using the natural agents. International Journal of Collaborative Research on Internal Medicine \& Public Health. 2018;10(2):0-. 